Article

\title{
Speed and Pressure Controls of Pumps-as-Turbines Installed in Branch of Water-Distribution Network Subjected to Highly Variable Flow Rates
}

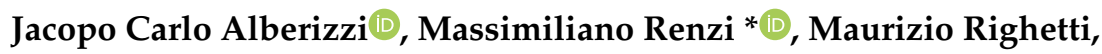 \\ Giuseppe Roberto Pisaturo ${ }^{D}$ and Mosè Rossi ${ }^{D}$ \\ Faculty of Science and Technology, Free University of Bozen-Bolzano, Piazza Università 5, I-39100 Bolzano, Italy; \\ jacopo.alberizzi@natec.unibz.it (J.C.A.); maurizio.righetti@unibz.it (M.R.); \\ giusepperoberto.pisaturo@unibz.it (G.R.P.); mose.rossi@unibz.it (M.R.) \\ * Correspondence: massimiliano.renzi@unibz.it; Tel.: +39-0471-017816
}

Received: 8 November 2019; Accepted: 10 December 2019; Published: 12 December 2019

check for updates

\begin{abstract}
The use of Pumps-as-Turbines (PaTs) to replace hydraulic turbines as energy-recovery units in industrial and civil applications is widening the penetration of hydropower in small-scale plants. PaTs show advantages in terms of installation costs and the availability of solutions. Water Distribution Networks (WDNs) represent a potential application where PaTs can be installed to recover water-pressure energy. In this work, a MATLAB@-Simulink model of a WDN branch located in South-Tyrol (Italy) was developed. The flow rate of the WDN was assessed though a measurement campaign showing high daily variability, which negatively affect PaT performance. To let the machine operate close to the Best Efficiency Point (BEP), four different operating strategies were studied to meet the constraint of a fixed pressure equal to 4 bar downstream the WDN branch, required to supply water to users. A PaT speed control strategy was implemented, granting better exploitation of flow rates even in the presence of high daily fluctuations. Energy recovery was $23 \%$ higher than that of the reference thanks to an advanced strategy based on controlling PaT rotational speed when the flow rate is smaller than that of the design, and operating in off-design conditions when flow rate is higher than that of the BEP.
\end{abstract}

Keywords: small-scale hydropower; pumps-as-turbines; water-distribution networks; energy recovery; MATLAB@-Simulink model

\section{Introduction}

The effects of climate change have forced us to reconsider actual energy scenarios: the use of renewable sources is a viable solution to produce electrical energy in a cleaner and more sustainable way, as well as to avoid irreversible effects on the environment [1]. Among alternative resources, energy-recovery interventions in both civil and industrial plants are being adopted with the aim of recovering part of the energy content of a fluid or liquid that would otherwise be wasted. In such a context, the implementation of innovative solutions on the urbanization level, like the ones discussed in [2], are becoming of interest.

Within various clean and renewable sources that are employed for producing energy, water is one of the most traditional and widespread [3,4]. However, most geographical locations where large-scale hydropower plants could be built have already been exploited. In addition, further improvements are no longer effective since technologies used in this field have reached a high level of development.

Because of this, current interest is directed at the construction of small-scale hydropower plants and hydraulic machines with novel or traditional design in order to be used in this sector [5-7]. 
In urban areas, water-treatment plants and Water Distribution Networks (WDNs) constitute a very important field in which energy-saving interventions can be performed $[8,9]$. Generally, Pressure Reducing Valves (PRVs) are installed inside WDNs in order to manage water pressure according to end-user demands. Moreover, leakages have a directly increasing relation with water pressure $[10,11]$. Novel techniques like hybrid evolutionary algorithms are able to detect WDN leakages and correlate them to the local level of water pressure [12]. PRVs also grant a lower risk of possible failures along pipelines that could lead to considerable water losses from the network. Several studies related to the use, location, and management of PRVs have been performed in order to optimize WDN operation. Saldarriaga et al. [13] proposed a multiobjective optimization approach to select the optimal location and setting of PRVs in a WDN, which was then tested in two different networks. Wright et al. [14] developed an optimization method capable of controlling PRVs through dynamic topology, showing interesting results in terms of both pressure-reduction capabilities and losses.

However, the use of PRVs does not involve direct energy recovery of available potential water energy. In this context, centrifugal pumps that operate in reverse mode, namely, Pumps-as-Turbines (PaTs), are taking the field and can be considered a viable technical solution for energy-recovery purposes. PaTs have been identified as low-cost alternatives when compared to conventional hydraulic turbines in small-hydropower applications up to $500 \mathrm{~kW}$, achieving considerably low PayBack Period (PBP) of project investment [15]. In addition, equipment cost is significantly reduced [16], making PaTs an outstanding solution for small-hydropower schemes. Besides the low cost of PaTs, other advantages regard (i) their applicability in a wide range of applications in terms of both flow rates and heads, (ii) quite large availability of spare parts, and (iii) easy installation with less constructive complexity.

Many drawbacks when dealing with PaTs are related to the lack of performance data from pump manufacturers when hydraulic machines operate in reverse mode [17]. One of the main challenges of $\mathrm{PaT}$ selection regards their performance prediction in turbine mode, considering both Best Efficiency Point (BEP) and off-design operating conditions [18]. Rossi et al. [19] used Artificial Neural Networks (ANNs) to predict the performance of PaTs operating in turbine mode knowing the design data in pump mode. Venturini et al. [20] developed a physics-based model in order to obtain performance curves of PaTs operating in turbine mode starting from design data in pump mode.

Nowadays, Computational Fluid Dynamics (CFD) simulations play a key role to predict and investigate both the performance and internal fluid behavior of PaTs. CFD models have been used to simulate the operation of PaTs in both pump and turbine modes, which were subsequently validated through experimental tests in order to prove their effectiveness [21,22]. However, one of the biggest issues related to CFD simulations of pumps and PaTs is the correct and reliable generation of a 3D CAD geometry. Pump manufacturers hardly provide the main information of both impeller and volute, thus making the generation of an accurate 3D model very complex. Nowadays, CADCAM software and 3D scanners facilitate the construction of a proper geometrical model and, thus, to run reliable CFD simulations that can be validated with experiment results [23]. With regard to the geometrical optimization of PaTs in turbine mode, some modifications on impeller geometry with respect to the original design of the pump have been proposed in order to improve its performance. Wang et al. [24] proposed a method based on the evaluation of both inlet and outlet blade angles to design a special impeller with forward-curve blades that increase PaT performance when operating in turbine mode. Experiment results showed that the proposed model correctly identified the BEP of the PaT with the new impeller design.

The use of PaTs as energy-recovery units has mainly been applied in WDNs [25]. WDNs constitute typical case studies where the control of pressure inside network branches through PRVs is crucial, as previously reported [26-30]. De Marchis et al. [31] developed a dynamic mathematical model for intermittent WDNs in the city of Palermo located in Sicily (Italy): they integrated PaTs in the model and demonstrated their effectiveness to recover energy that would otherwise be wasted. Carravetta et al. [32] studied possible different hydraulic conditions that can occur in WDNs and they examined five different regulation systems in order to overcome them. 
Recently, some works related to both speed and pressure control strategies of PaTs operating with highly variable flow rates have been published, as discussed hereinafter. Pressure control in a single branch of a WDN is mandatory since it grants the water supply to all users connected to the network. Delgado et al. [33], and Mercier et al. [34] highlighted that one of the biggest limitations of PaT application is their operability, which is strongly dependent on the elaborated flow rate. In a WDN, flow rate varies according to user demands that change frequently during the day and throughout the year, especially in small municipality networks.

In this work, a preliminary MATLAB@-Simulink model described in [35], which proposed a fixed-speed control strategy for PaTs installed in a WDN, was extended and further developed, focusing attention on possible PaT management strategies with the aim of optimizing energy recovery.

In particular, four different self-regulating strategies that let PaTs operate properly were developed in order to control rotational speed according to effective available flow rates; granting minimum pressure downstream, PaTs are capable of providing water to both householders and industrial users. The main novelty of this work regards the continuous adjustment of PaT operating conditions in order to always operate close to the BEP, as well as when flow characteristics change quickly. Sensitivity analysis was performed, also considering a reduction of WDN operating pressure in order to show the effectiveness of speed control regulation based on BEP tracking.

A specific measurement campaign was carried out in the same WDN to record flow-rate variations of which the average hourly values were obtained in one week. Measured flow rates in a specified branch that was the most affected by their variation were used as input values of the model, while pressure downstream of the PaT system was kept constant. Furthermore, pressure values upstream of PaTs inserted in the model were checked and compared to the useful head in order to analyze the feasibility of the installation.

This paper is structured as follows: Section 2 describes the case study, providing an overview of the site of interest, such as flow rates obtained during the measurement campaign, giving useful information on the proper installation layout. Section 3 presents a model used to select a PaT suitable for the analyzed branch [36]. In addition, PaT performance was investigated through the model presented and validated by Rossi et al. [21]. The MATLAB@-Simulink model is also described in detail in this section, focusing attention on the main blocks employed in its development. Section 4 presents four cases that show different operating control strategies of PaTs installed in the WDN branch. Per each case, overall PaT performance and potential energy recovery are discussed in Section 5. Finally, Section 6 reports the conclusions of our work.

\section{Case Study}

A branch of the WDN located in the municipality of Laives in South-Tyrol (Italy) was chosen because of its high flow-rate variability that allowed to test possible management strategies aimed at increasing energy-recovery potential. The daily trend of flow rates inside the analyzed WDN branch was constant all week long, as also found in other case studies on similar networks of small municipalities [26,32]. In this section, the test site and flow rates obtained in the measurement campaign are presented and discussed.

Laives is a small town located at an altitude a.s.l. of $258 \mathrm{~m}$. Its WDN is fed by two tanks that supply about 18,000 inhabitants. The tanks are placed at $108 \mathrm{~m}$ of altitude upstream of the town. The WDN is composed of 16 branches: its structure consists of a central part of which the various branches form a grid that guarantee operation in the case of small failures, and then it moves towards peripheral areas as shown in Figure 1. 


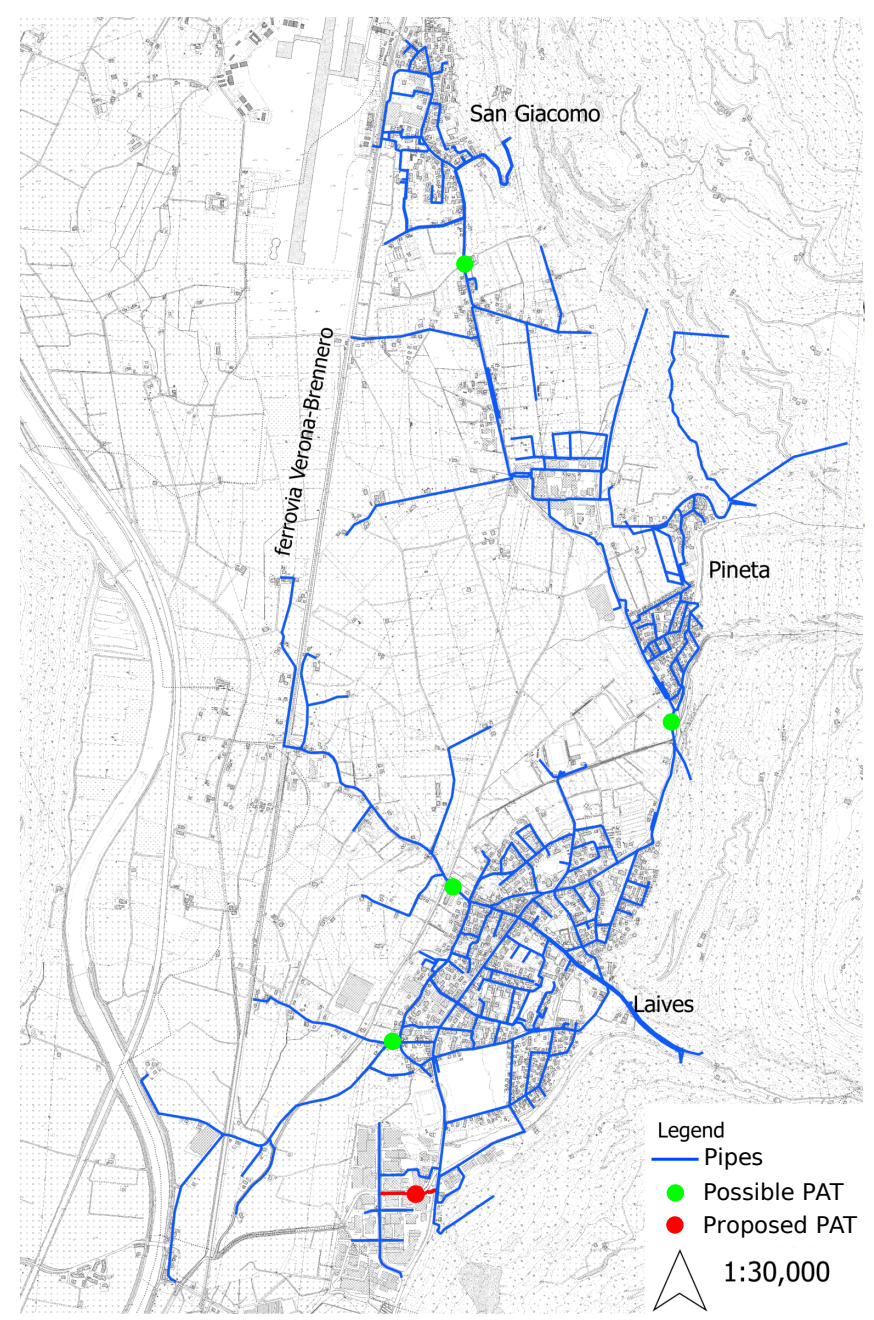

Figure 1. Water Distribution Network (WDN) of Laives (South Tyrol, Italy, DMS: $46^{\circ} 25^{\prime} 39.42^{\prime \prime} \mathrm{N}$, $11^{\circ} 20^{\prime} 25.72^{\prime \prime} \mathrm{E}$ ) where analyzed branch is highlighted in red. Green dots are possible Pump-as-Turbine (PaT) positions. Red dot is proposed PaT position.

Flow rate depends on user demands, while pressure inside pipes depends on both useful head and water demand. PRVs were installed along the network in order to guarantee a pressure of 4 bar downstream of each WDN branch, which was imposed by legislation of the Autonomous Province of Bozen/Bolzano [37] in order to supply water to both householders and industrial users. Similar laws limiting the operating pressure of WDNs are in force in the rest of Italy, as well as in other countries. However, WDN pressure control through PRVs involves unexploited potential energy that is wasted. By replacing PRVs with PaTs, pressure inside the WDN is controlled, and the recovered energy, which would otherwise be wasted, can be converted to electricity and used for the self-consumption of WDN plants or for other purposes.

In this case study, both water flow rate and pressure in the selected branch of the WDN were recorded through a measurement campaign performed by the authors of this work with the local municipality of Laives. The test campaign lasted one week, and values were recorded every 5 min. A branch of the analyzed WDN, highlighted in red in Figure 1, was selected for this study since it showed the highest variability of flow rates in the experiment campaign, which is the most challenging case to optimize the use of PaTs for this kind of application. Moreover, this branch connects a group of both residential and industrial end users to the main WDN.

Average hourly flow-rate values, which were measured between 6:00 and 20:30, were chosen to run the simulations. Flow rate before 6:00 and after 20:30 was not considered for the PaT selection process described in Section 3, as exploitable flow rates are too low to be significantly exploited, thus 
affecting the PaT selection process without valuable energy-recovery potential. Table 1 reports the average values of daily water flow rates, and Figure 2 displays their trends along with raw data in the background.

Table 1. Average hourly flow rates inside WDN branch from 6:00 to 20:30.

\begin{tabular}{|c|c|c|c|c|c|c|c|c|c|c|c|c|c|c|c|}
\hline Hour & $6: 00$ & 7:00 & $8: 00$ & 9:00 & $10: 00$ & $11: 00$ & $12: 00$ & $13: 00$ & $14: 00$ & $15: 00$ & $16: 00$ & $17: 00$ & $18: 00$ & $19: 00$ & $20: 30$ \\
\hline$Q\left(\mathrm{~m}^{3} / \mathrm{h}\right)$ & 14.67 & 19.57 & 16.40 & 14.94 & 13.24 & 11.17 & 13.56 & 13.56 & 12.18 & 10.24 & 12.10 & 11.51 & 18.58 & 19.34 & 14.25 \\
\hline
\end{tabular}

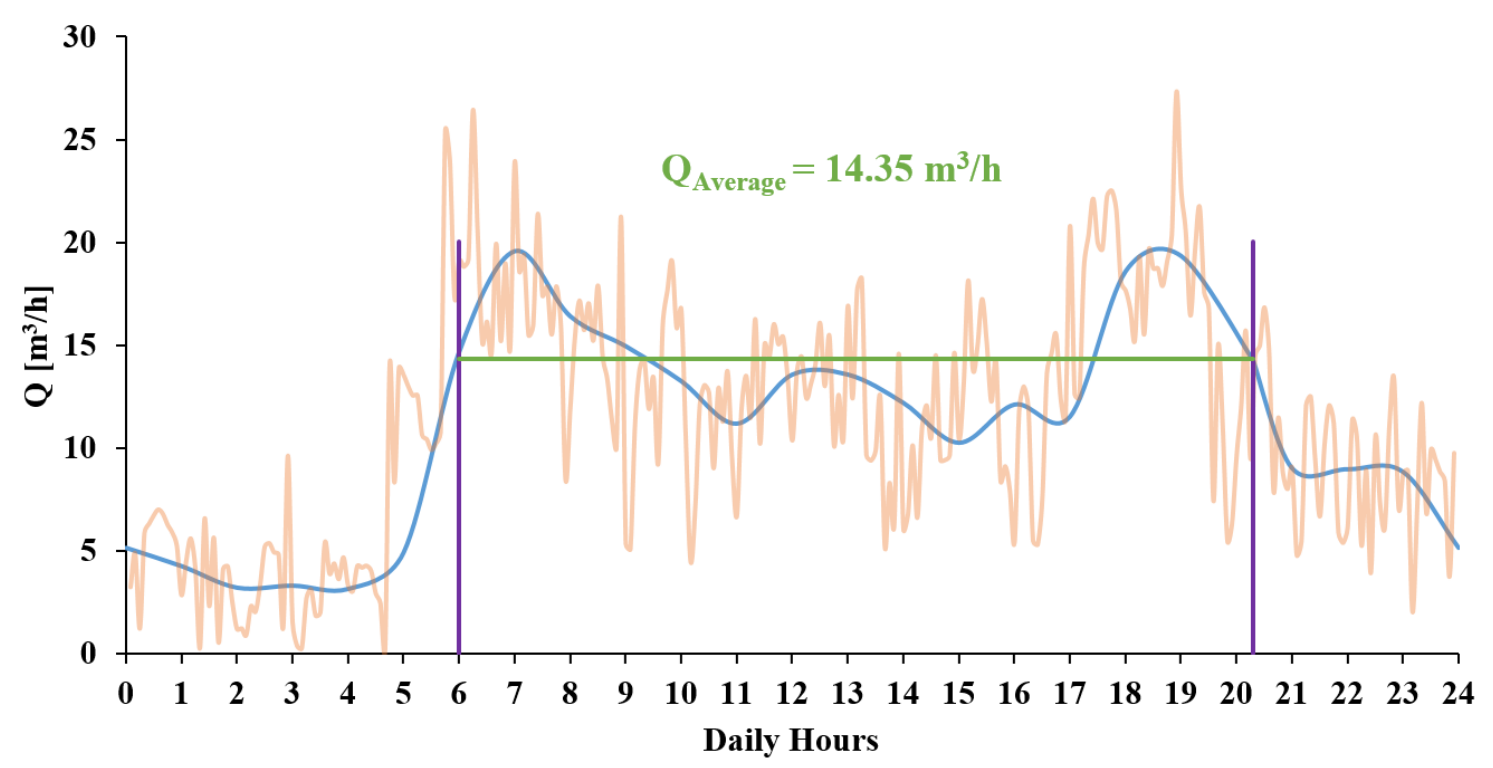

\section{- Filtered Flow Rate $\quad$ Real Flow Rate}

Figure 2. Daily flow-rate trends of analyzed WDN branch (raw data in background).

The average flow rate of the WDN branch in the selected operating hours, considering values listed in Table 1, was equal to $14.35 \mathrm{~m}^{3} / \mathrm{h}$. A useful net head of about $45.6 \mathrm{~m}$, considering all losses that water encounters during its path and downstream pressure fixed to $4 \mathrm{bar}$, is available; thus, these values were used as BEP data of the PaT. Due to the predicted values of both flow rate and head at the rated operating conditions of the PaT in turbine mode, a configuration with only one PaT, or two PaTs in parallel, would lead to the selection of a machine with very low specific speed, which typically involves lower hydraulic efficiency, thus not granting the desired performance. Indeed, correlation between the specific speed of the PaT and its mechanical efficiency was obtained by [38]: the lower the specific rotational speed is, the lower the mechanical efficiency. Therefore, a configuration with two PaTs installed in series was chosen in order to achieve high performance using a single-stage hydraulic machine, thus halving the net head exploited by each PaT to $22.8 \mathrm{~m}$.

Once BEP values of the PaT were chosen, a proper evaluation of the PaT BEP in pump mode was performed and is explained in Section 3, as well as the analytical method used to evaluate both characteristic $(Q-H)$ and efficiency $(Q-\eta)$ curves of PaTs operating in turbine mode that were implemented in the MATLABC-Simulink model.

\section{PaT Performance}

\subsection{Selection of PaT Operating at Rated Conditions in Turbine Mode}

PaTs inserted in the WDN model were selected following the procedure described in detail in [36] to which the reader is referred for further information.

This model relies on a set of correlations, developed by using 59 experiment data of PaTs operating in turbine mode that allow to link the operating conditions of a PaT at BEP in pump mode to the 
ones of the same machine when operating in turbine mode. This is fundamental to select proper machine typology and size since pump manufacturers only supply PaT performance in direct mode. The model is based mainly on PaTs having radial and mixed-flow configurations. In this case, the model was fed with the design data of the PaT in turbine mode obtained in Section 2 and used to identify corresponding operating data in pump mode that can be used for proper pump selection. Equations (1) and (2) constitute a set of two equations in two variables that describe the specific speed $\left(N_{\mathrm{Sp}}\right)$ and the specific diameter $\left(D_{\mathrm{Sp}}\right)$ in pump mode using correlations reported in [36].

$$
\begin{aligned}
N_{\mathrm{Sp}} & =\frac{N_{\mathrm{St}}}{0.9051} \\
D_{\mathrm{Sp}} & =\frac{D_{\mathrm{St}}}{0.9436}
\end{aligned}
$$

Once both $N_{\mathrm{Sp}}$ and $D_{\mathrm{Sp}}$ are evaluated, the values of both rotational speed and outer impeller diameter of the PaT are calculated in order to evaluate both pump flow rate and head by coupling Equations (3) and (4), respectively. The guess values of both rotational speed and outer impeller diameter were considered as an initial attempt; subsequently, through an iterative process, the final results were obtained.

$$
\begin{aligned}
& N_{\mathrm{Sp}}=\omega \cdot \frac{\sqrt{Q_{\mathrm{p}}}}{\sqrt[4]{\left(g \cdot H_{\mathrm{p}}\right)^{3}}} \\
& D_{\mathrm{Sp}}=D \cdot \frac{\sqrt[4]{g \cdot H_{\mathrm{p}}}}{\sqrt{Q_{\mathrm{p}}}}
\end{aligned}
$$

At this point, it was possible to select the proper machine from the catalogues of pump manufacturers, having both rotational speed and outer impeller diameter close to the ones previously obtained, so that the main characteristics of the pump at BEP, including its mechanical efficiency, are now known. Equation (5) allows to evaluate the mechanical efficiency of the PaT operating in turbine mode $\left(\eta_{\mathrm{t}}\right)$ by knowing both the $N_{\mathrm{Sp}}$ and the $\eta_{\mathrm{p}}$ of the pump. Finally, all main design parameters of the PaT, operating at its BEP in both pump and turbine modes, were then available and are listed in Table 2. The obtained pump-mode data are the same as the Calpeda N32-125 A/A: for this reason, this hydraulic machine was selected.

$$
\eta_{\mathrm{t}}=0.7933 \cdot N_{\mathrm{Sp}}+0.605 \cdot \eta_{\mathrm{p}}-0.09246 \cdot N_{\mathrm{Sp}}{ }^{2}-0.8254 \cdot\left(N_{\mathrm{Sp}} \cdot \eta_{\mathrm{p}}\right)+0.3936 \cdot \eta_{\mathrm{p}}{ }^{2}
$$

Table 2. Best Efficiency Point (BEP) values of PaT in pump and turbine modes.

\begin{tabular}{ccc}
\hline & Pump Mode & Turbine Mode \\
\hline Flow rate $\left(\mathrm{m}^{3} / \mathrm{h}\right)$ & 13 & 14.35 \\
Head $(\mathrm{m})$ & 20 & 22.8 \\
Mechanical efficiency (-) & 0.72 & 0.69 \\
Rotational speed (rpm) & 2900 & 2900 \\
Specific speed (rad/s) & 0.35 & 0.29 \\
Impeller diameter $(\mathrm{m})$ & 0.121 & 0.121 \\
\hline
\end{tabular}

\subsection{Characteristic Curves in Turbine Mode}

The definition of the PaT BEP is not enough to characterize the behavior of this hydraulic machine when dealing with off-design operating conditions. For this reason, the model used to predict the characteristic curves of PaTs is based on previous work by Rossi et al. [21], to which the reader is referred for further information. 
Specifically, an analytical model based on experiment data related to 32 different PaTs was used to define two polynomial equations that allow end users to reconstruct the performance curves of the $\mathrm{PaT}$ in terms of both characteristic and efficiency curves.

Since the model is based on nondimensional analysis, correlations could also be adopted for other machines that work in fluid dynamic similarity conditions, both in design and off-design operation. Equation (9) represents the nondimensional characteristic curve (flow coefficient $\phi$ vs. head coefficient $\psi$ ), while Equation (10) describes the efficiency curve (flow coefficient $\phi$ vs. mechanical efficiency $\eta)$. Both of them are extensively described in [21]. For clarity, flow coefficient $\phi$, head coefficient $\psi$, and mechanical efficiency $\eta$ were evaluated through Equations (6)-(8), respectively. Regarding the involved physical magnitudes, $Q$ is expressed in $\left(\mathrm{m}^{3} / \mathrm{s}\right), \omega$ in $(\mathrm{rad} / \mathrm{s}), D$ in $(\mathrm{m}), P_{\mathrm{m}}$ in $(\mathrm{W}), \rho$ in $\left(\mathrm{kg} / \mathrm{m}^{3}\right), g$ in $\left(\mathrm{m} / \mathrm{s}^{2}\right)$ and $H$ in $(\mathrm{m})$.

$$
\begin{aligned}
\phi & =\frac{Q}{\omega \cdot D^{3}} \\
\psi & =\frac{g \cdot H}{\omega^{2} \cdot D^{2}} \\
\eta & =\frac{P_{\mathrm{m}}}{\rho \cdot g \cdot Q \cdot H}
\end{aligned}
$$

These equations provide correlations between (i) flow coefficient $\phi$ vs. head coefficient $\psi(\phi-\psi$ curve), and (ii) flow coefficient $\phi$ vs. efficiency $\eta$ ( $\phi-\eta$ curve), both normalized with respect to the same magnitudes achieved at BEP conditions in turbine mode, namely, $\phi_{B E P}, \psi_{B E P}$ and $\eta_{B E P}$, as Figure 3 shows. These curves allows PaT end users to globally characterize the performance of the machine in both design and off-design conditions according to the nominal operational data of the site in which the PaT is installed.

$$
\begin{aligned}
\frac{\psi}{\psi_{B E P}}= & 0.2394 \cdot\left(\frac{\phi}{\phi_{B E P}}\right)^{2}+0.769 \cdot\left(\frac{\phi}{\phi_{B E P}}\right) \\
\frac{\eta}{\eta_{B E P}}= & -1.9778 \cdot\left(\frac{\phi}{\phi_{B E P}}\right)^{6}+9.0636 \cdot\left(\frac{\phi}{\phi_{B E P}}\right)^{5}-13.148 \cdot\left(\frac{\phi}{\phi_{B E P}}\right)^{4}+ \\
& +3.8527 \cdot\left(\frac{\phi}{\phi_{B E P}}\right)^{3}+4.5614 \cdot\left(\frac{\phi}{\phi_{B E P}}\right)^{2}-1.3769 \cdot\left(\frac{\phi}{\phi_{B E P}}\right)
\end{aligned}
$$
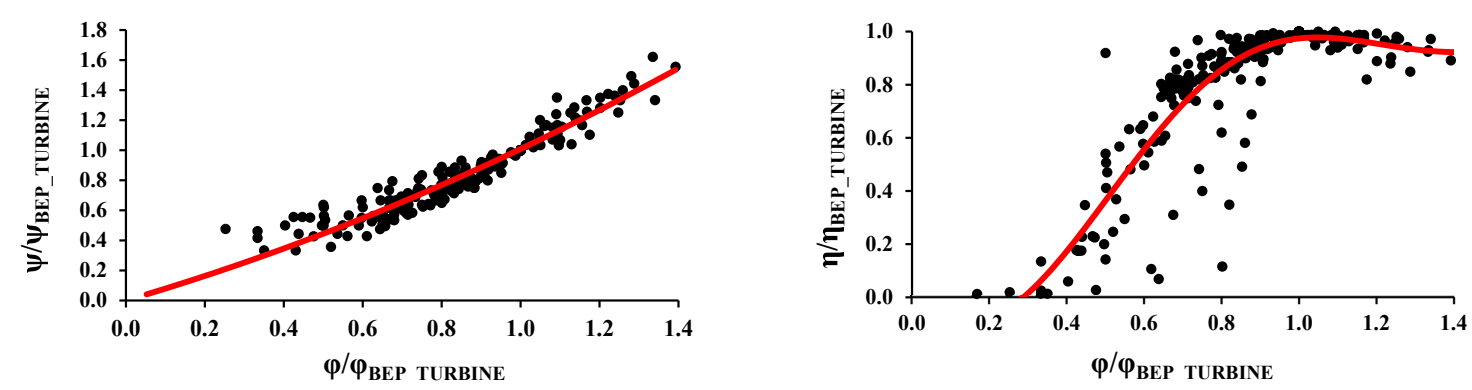

Figure 3. Nondimensional (left) characteristic and (right) efficiency curves obtained by [21].

Finally, using the BEP values of the PaT selected for the test case (see Table 2) and applying dimensional analysis, it is possible to define design and the off-design operating data of the machine in turbine mode, as listed in Table 3. Figure 4 shows the characteristic curve of the selected pump in turbine mode. A PRV is always installed downstream of the last PaT in order to guarantee downstream pressure of 4 bar whenever a hydraulic machine is not able to exploit all available head. 
Table 3. PaT performance evaluated through models described in [21,36].

\begin{tabular}{|c|c|c|c|c|c|c|}
\hline BEP Flow Rate Offset (\%) & Flow Rate $\left(\mathrm{m}^{3} / \mathrm{h}\right)$ & $\phi(-)$ & Head (m) & $\psi(-)$ & Mechanical Efficiency (-) & Mechanical Power (KW) \\
\hline$-40 \%$ & 8.86 & 0.0046 & 12.50 & 0.0908 & 0.38 & 0.12 \\
\hline$-30 \%$ & 10.33 & 0.0053 & 14.95 & 0.1086 & 0.50 & 0.21 \\
\hline$-20 \%$ & 11.80 & 0.0061 & 17.52 & 0.1273 & 0.59 & 0.33 \\
\hline BEP & 14.35 & 0.0074 & 22.80 & 0.1656 & 0.69 & 0.62 \\
\hline$+10 \%$ & 16.24 & 0.0084 & 25.90 & 0.1882 & 0.67 & 0.77 \\
\hline$+20 \%$ & 17.71 & 0.0091 & 28.91 & 0.2100 & 0.66 & 0.92 \\
\hline
\end{tabular}

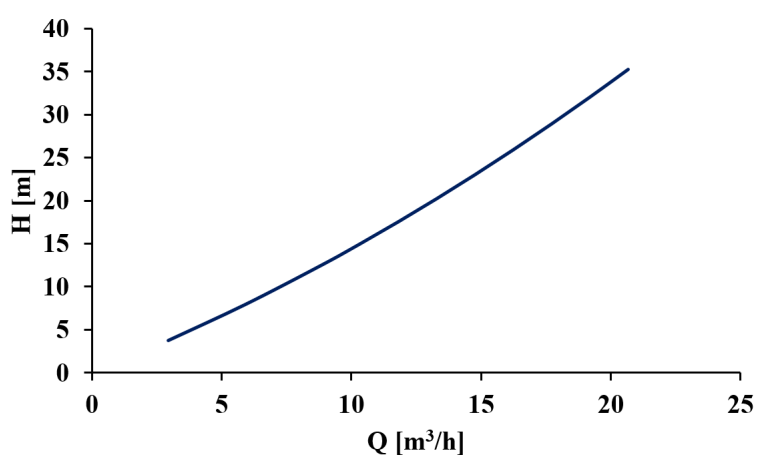

Figure 4. Q-H characteristic curve of selected pump in turbine mode.

\subsection{MATLAB@-Simulink Model}

A MATLAB@-Simulink model related to a branch of the WDN located in Laives, South Tyrol (Italy) was developed in order to evaluate different PaT operating strategies and select the best in terms of the highest energy recovery. To build the model, standard MATLAB৫-Simulink toolboxes were used, as well as those of the Simscape Fluids toolbox. These allow to properly design and simulate fluid systems and hydraulic circuits.

The model is composed of various blocks that simulate the structure and dynamic of the analyzed WDN branch, including flow meters, PaTs, pipes, pressure probes, and tanks. Figure 5 shows a sketch of the simulated system. The most important parts of the model are Blocks A, B, C, D, and E, as Figure 6 shows.

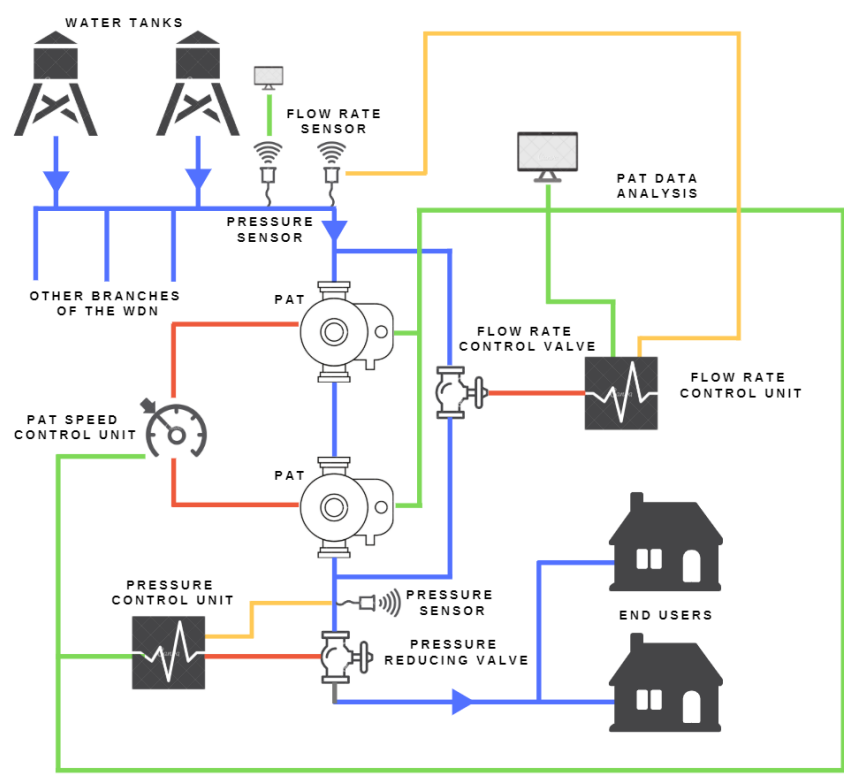

Figure 5. Overview diagram of simulated system. 


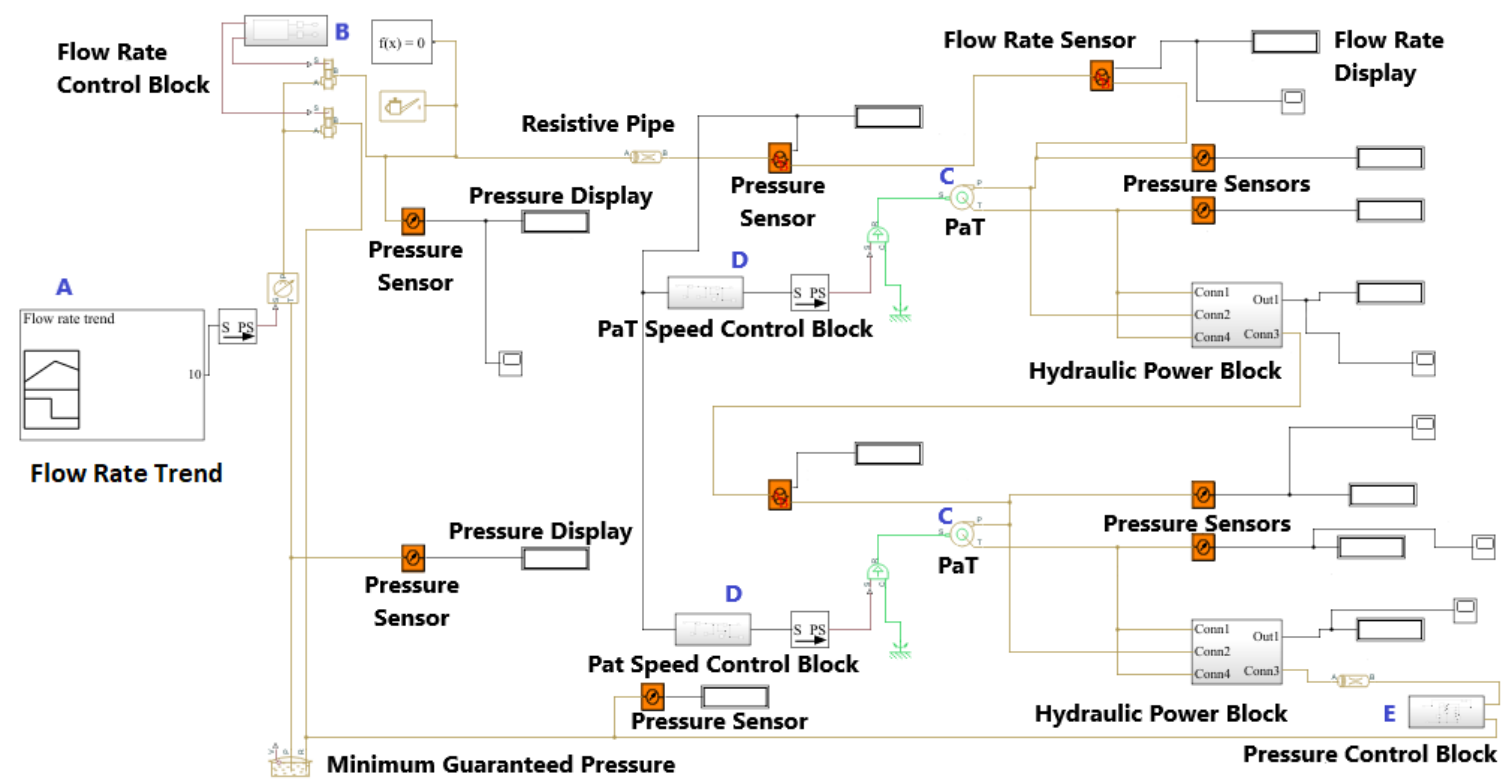

Figure 6. MATLABC-Simulink model of selected WDN branch.

The profile of the daily flow-rate trend related to the analyzed WDN branch, which is reported in Table 1 and shown in Figure 2, is imported in Block A that generates the input signal of the flow rates, as shown in Figure 7.

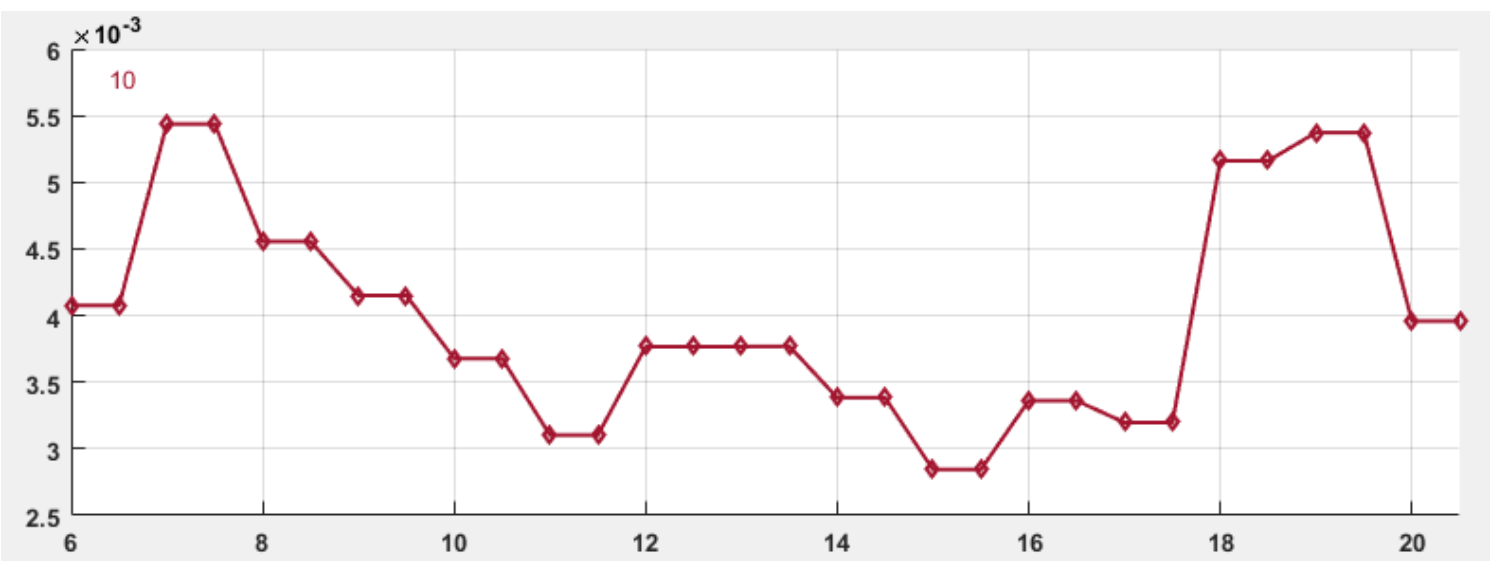

Figure 7. Flow-rate signal (Y-axis) expressed in $\left(\mathrm{m}^{3} / \mathrm{s}\right)$ generated by Block A of MATLAB@Simulink model.

Flow-rate control is embedded in Block B and it simulates a valve that bypasses the excess of flow rate that cannot be processed by PaTs when it is too high or when the constraint of the downstream pressure is not met.

Two PaTs inserted in series constitute Block $C$. The element related to the centrifugal pump, which is included in the MATLABC-Simulink library, was chosen and its inlet and outlet sections were reversed in order to simulate the behavior of a PaT. PaT performance when operating in both design and off-design conditions, which were evaluated through the models described in this section and summarized in Table 3, were inserted in Block C.

The self-regulating speed control of PaTs was implemented in Block D. According to the employed operating strategies, which are described in Section 4, Block D regulates PaT rotational speed by either checking downstream pressure or optimizing their performance. Finally, Block E resembles a pressure-control system of a traditional PRV. The PRV is fundamental to keep the downstream pressure of the WDN constant and equal to 4 bar when the two PaTs cannot dissipate all available 
head, for example, when the available flow rate is lower than the rated one. A scheme of the flow rate and pressure-regulation control is shown in Figure 8.

Each block is linked with lines that resemble pipes of the WDN branch, where both internal pipe diameter $(0.2 \mathrm{~m})$ and surface-roughness height $\left(15 \times 10^{-6} \mathrm{~m}\right)$ were inserted according to pipe specifications to take into account pressure drops. In addition, flow meters and pressure probes were added in order to monitor the respective values of flow rate and pressure, as well as to prove the effectiveness of the energy-recovery strategies that are analyzed in this work.

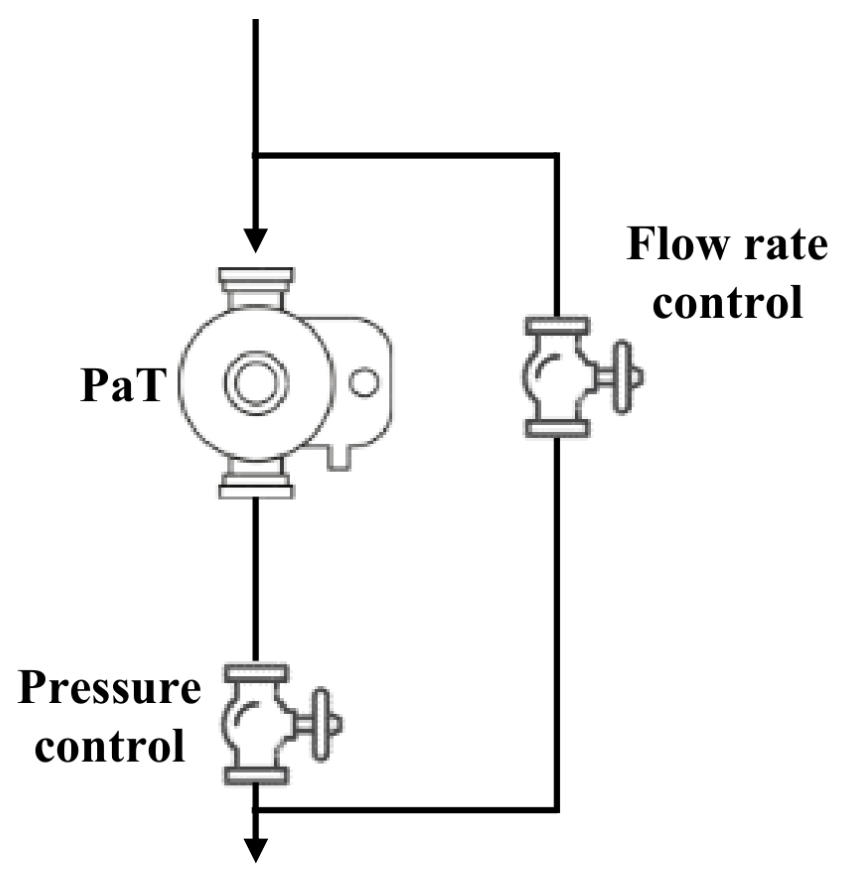

Figure 8. Scheme of flow-rate and pressure-control system.

\section{Results and Comments}

In this work, four different management strategies are proposed in order to optimize energy recovery in the analyzed WDN branch by means of PaTs considering the downstream pressure constrained at 4 bar. Table 4 lists the different management strategies and operating pressures that have to be guaranteed downstream from the WDN branch. In particular, Blocks D that are related to flow-rate control define the operation of the WDN branch with speed regulation.

Table 4. Four operating strategies analyzed in this work.

\begin{tabular}{lcc}
\hline & Operating Strategy & Pressure Constraint (Bar) \\
\hline Case 1 & Flow-rate control & 4 \\
\hline Case 2 & $\begin{array}{l}\text { Flow-rate and } \\
\text { speed control }\end{array}$ & 4 \\
\hline Case 3 & Speed control & 4 \\
\hline Case 4 & $\begin{array}{l}\text { Flow-rate and } \\
\text { speed control }\end{array}$ & 3.5 \\
\hline
\end{tabular}

Among the listed cases, the last one analyzes the effect of a possible reduction of downstream operating pressure down to 3.5 bar. Even though the downstream pressure of a WDN has to be equal or close to 4 bar to guarantee the supply of water to both householders and industrial activities, the choice of reducing downstream pressure could lead to (i) a decrease of water losses along WDN pipes and (ii) a higher head exploited by the PaTs. Almost all the WDNs in Italy have a high percentage 
of water losses, reaching an average value of $36 \%$, due to the presence of old and spoiled pipes that are symptoms of incorrect control and maintenance [39]. For this reason, the decrease of downstream pressure could be a viable solution to reduce water losses, not affecting water supply in any way.

\subsection{Case 1: Basic Flow-Rate Control Strategy}

In the first case, simple flow-rate control through bypass valves was implemented in order to guarantee an operating pressure of 4 bar downstream of the WDN branch. In this case, Block B set the limit for the maximum allowable flow rate through PaTs to $14.35 \mathrm{~m}^{3} / \mathrm{h}$. If flow-rate demand was higher than $14.35 \mathrm{~m}^{3} / \mathrm{h}$, the head of each hydraulic machine would rise; thus, downstream pressure would drop below the value of 4 bar. Block B bypassed the excesses of flow rates in a secondary circuit to avoid an excessive drop of downstream pressure below the imposed limit. As shown in Figure 9, this operating strategy did not control PaT rotational speed, which was kept fixed to $2900 \mathrm{rpm}$. Hydraulic machines operate at their BEP only with $Q_{\mathrm{BEP}}$, while the operating point moves along the $Q-\eta$ curve when flow rate that is lower than that the BEP one is exploited. In this case, $Q_{\mathrm{BEP}}$ corresponds to the average flow rate of the analyzed WDN branch, as discussed in Section 2. When PaTs deal with off-design operating conditions, such as the ones indicated through Points 1 and 2 in Figure 9, mechanical efficiency decreases.

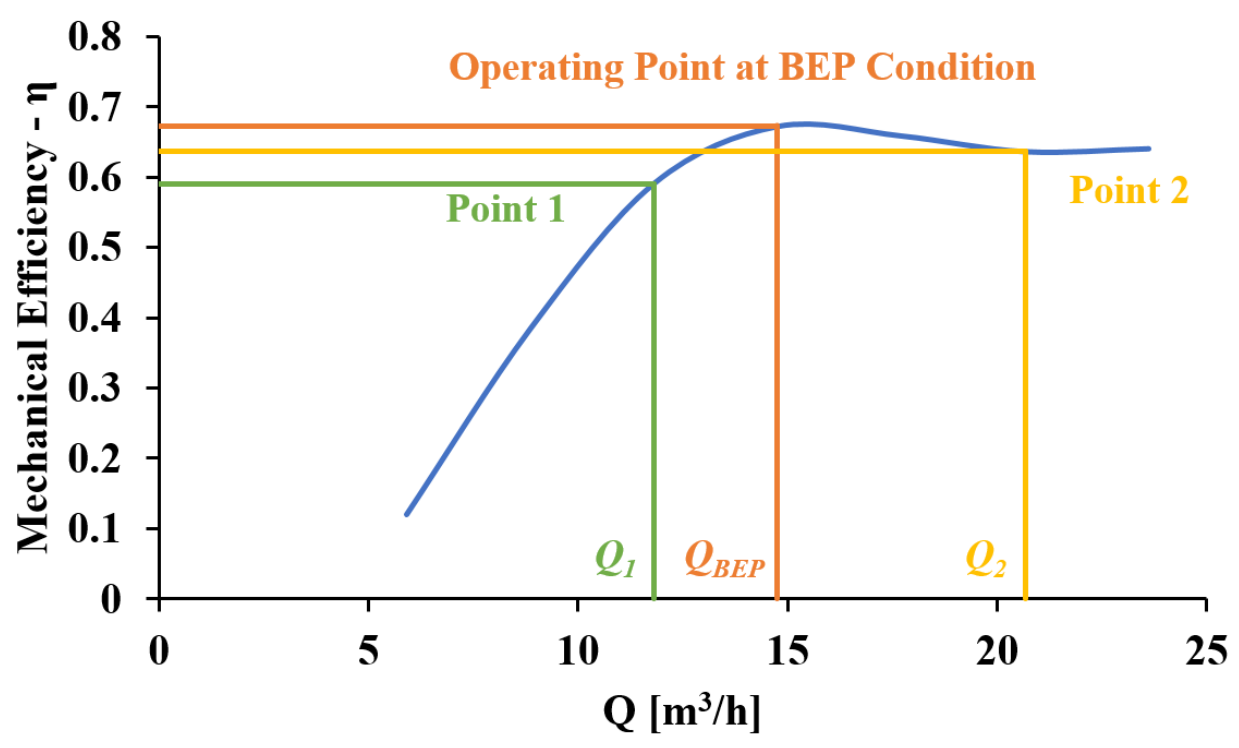

Figure 9. Efficiency curve $(Q-\eta)$ of selected PaTs at $2900 \mathrm{rpm}$.

\subsection{Case 2: Basic Flow-Rate and Speed Control}

In this second case, flow-rate excess corresponding to values above $14.35 \mathrm{~m}^{3} / \mathrm{h}$, which would cause an excessive decrease of downstream pressure, was bypassed by following the same procedure as that explained in Section 4.1. When flow rates were below $14.35 \mathrm{~m}^{3} / \mathrm{h}$, PaT rotational speed was reduced according to the exploited flow-rate value by applying affinity laws to let PaTs always operate at their BEP. Due to this, the efficiency curve $(Q-\eta)$ was shifted in order to match operative flow rate with the BEP condition, as shown in Figure 10. However, using this strategy, the amount of recovered energy increased by $1.5 \%$ compared to Case 1 ; this result was due to small variations of flow rates with respect to the maximum exploitable one of $14.35 \mathrm{~m}^{3} / \mathrm{h}$. 


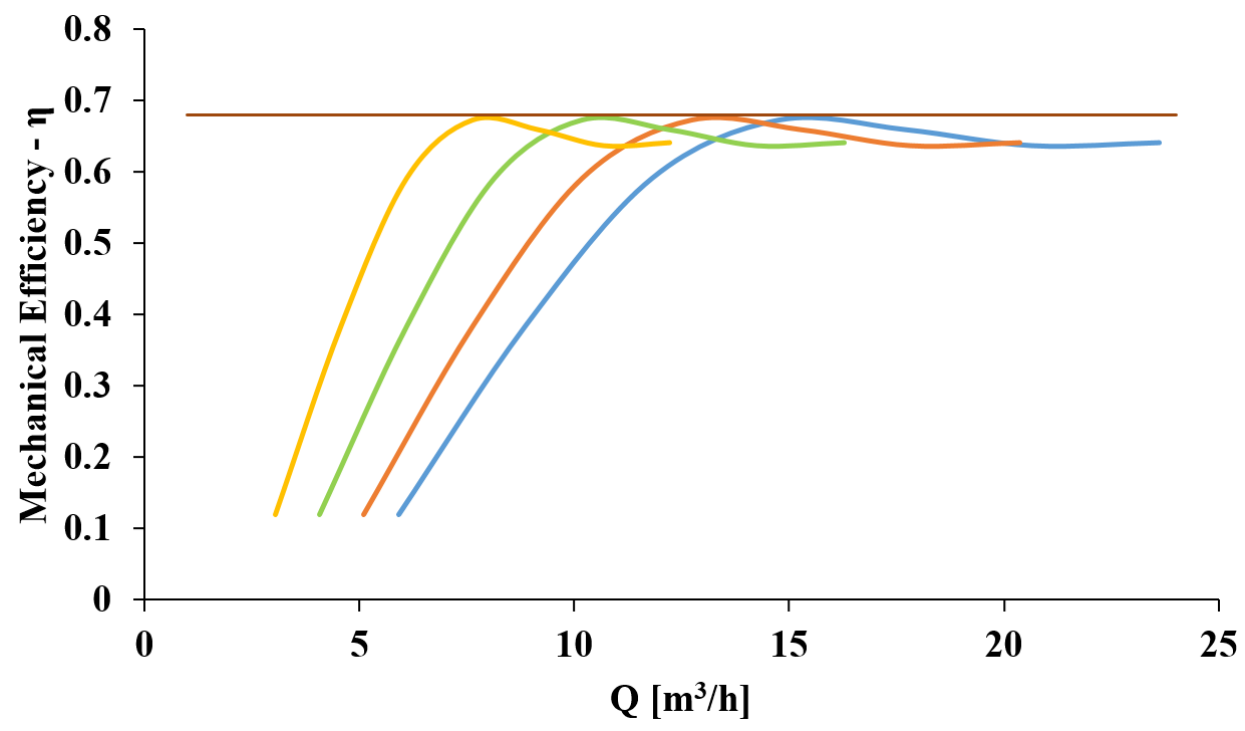

Figure 10. $Q-\eta$ curves of PaTs at different rotational speeds using affinity laws.

\subsection{Case 3: Advanced Speed and Flow Control}

This pressure-control strategy was executed with the aim of directly controlling PaT rotational speed. All flow rates imported in Block A were exploited, leading to the deactivation of Block B. In particular, when flow rate exceeded the value of $14.35 \mathrm{~m}^{3} / \mathrm{h}$, the rotational speed of PaTs automatically decreased in order to keep the downstream pressure fixed to 4 bar, following the same procedure explained in Section 4.2. Using this control strategy, the whole available flow rates were exploited at the expense of mechanical-efficiency reduction. The amount of recovered energy was $23 \%$ higher than the one obtained in Cases 1 and 2 due to the higher exploitation of flow rates since, in the previous ones, values higher than $14.35 \mathrm{~m}^{3} / \mathrm{h}$ were bypassed. However, neither PaT operated at its BEP when dealing with flow rates higher than the BEP one due to the constraint of downstream pressure fixed at 4 bar. Through analysis of the mechanical-efficiency trend when PaTs operate in off-design conditions, we can see how efficiency loss was limited when flow rates exceeded the one at $\mathrm{BEP}$, while it dropped when flow rate was lower than the BEP one, especially at extreme part-load conditions.

\subsection{Case 4: Basic Flow-Rate and Speed Control with Reduced WDN Pressure to 3.5 Bar}

As seen in Case 3, the flow-rate amount that could be exploited by PaTs plays a key role on deciding the best strategy in order maximize energy recovery. In particular, Case 2 demonstrated that small variations of flow rates below $14.35 \mathrm{~m}^{3} / \mathrm{h}$ do not justify the use of a PaT speed-control strategy based on BEP tracking.

Sensitivity analysis was performed by lowering the allowable downstream pressure value to 3.5 bar in order to show how speed-control regulation based on BEP tracking could work well when downstream pressure is varied. Indeed, the flow rate that could be exploited by PaTs increases, as well as the exploited head. Operating strategy was the same as the one described in Section 4.2, but in this case, an average flow rate of $15 \mathrm{~m}^{3} / \mathrm{h}$ was obtained, which was higher than the one of previous cases $\left(14.35 \mathrm{~m}^{3} / \mathrm{h}\right)$. Finally, results showed that this control strategy was the most effective since it led to energy recovery that was almost $11 \%$ higher than the one obtained in Case 3, where all flow rates were exploited by the PaTs.

\section{Energy and Economic Analysis}

Table 5 reports the energy recovery and the economic savings obtained per year together with the percentage relative differences with respect to Case 1. Moreover, it reports the amount of energy 
that could not be recovered by the PaTs for the operational constraints and that was dissipated by the PRV; finally, the same table shows the percentage of recovered energy in each case with respect to the wasted energy in the PRVs. Economic savings were evaluated considering an electricity price of $0.22 € / \mathrm{kWh}[40]$ and efficiency of frequency converters equal to $96 \%$ [41].

Very small differences were achieved between Cases 1 and 2, which was mainly due to the bypass of flow rates higher than $14.35 \mathrm{~m}^{3} / \mathrm{h}$ that would decrease downstream pressure below 4 bar. Even though Case 2 allowed PaTs to always operate at their BEP as shown in Figure 11, the high amount of bypassed flow rates significantly contributed to reducing energy recovery, thus reducing the effectiveness of the speed control applied to PaTs. The trend of energy recovery over the day and its ratio with respect to the wasted energy in the PRVs are shown in Figures 12 and 13.

Table 5. Energy recovery, economic savings, and percentage of recovered energy with respect to wasted energy in Pressure Reducing Valves (PRVs) obtained with four different operating strategies.

\begin{tabular}{cccccc}
\hline & $\begin{array}{c}\text { Energy Recovery } \\
\text { (kWh/Year) }\end{array}$ & $\begin{array}{c}\text { Economic Saving } \\
(\boldsymbol{(} / \text { /Year) }\end{array}$ & $\begin{array}{c}\text { \% with Respect } \\
\text { to Case 1 }\end{array}$ & $\begin{array}{c}\text { Not Recovered } \\
\text { Energy (kWh/Year) }\end{array}$ & $\begin{array}{c}\text { \% of Recovered } \\
\text { Energy }\end{array}$ \\
\hline Case 1 & 4637 & 979 & - & 7833 & 37 \\
Case 2 & 4706 & 994 & 1.5 & 7764 & 38 \\
Case 3 & 5699 & 1204 & 23 & 6771 & 46 \\
Case 4 & 6307 & 1332 & 36 & 6163 & 51 \\
\hline
\end{tabular}

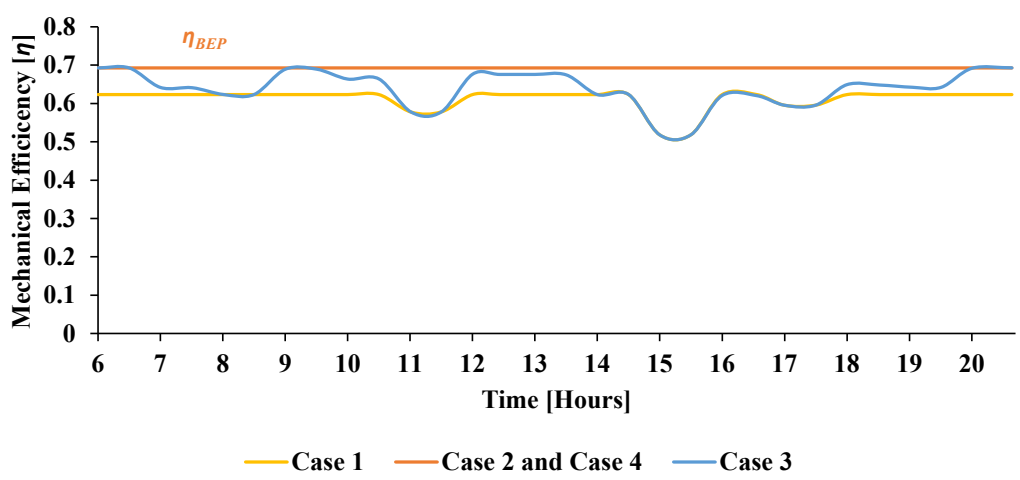

Figure 11. Comparison between mechanical-efficiency trends in different analyzed management strategies.

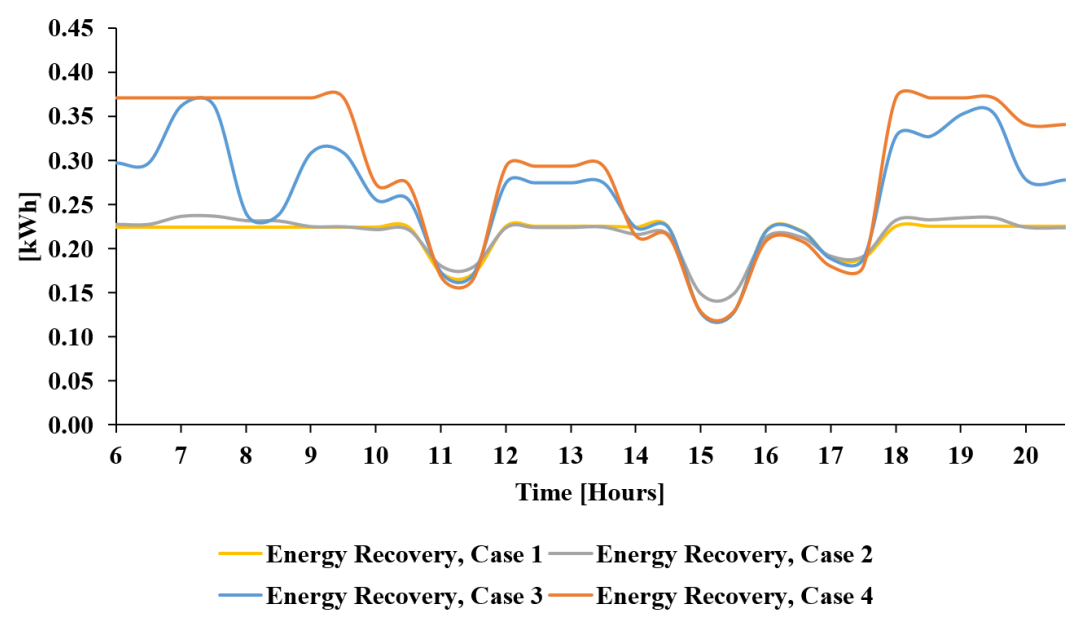

Figure 12. Trend of energy recovery over course of a day considering four different management strategies. 


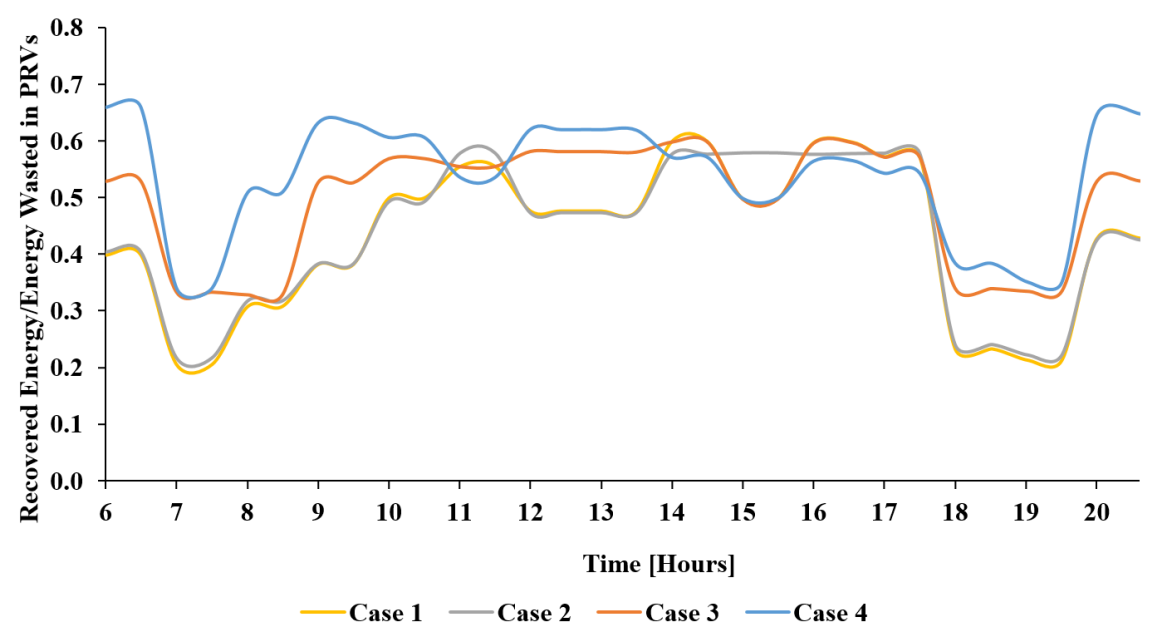

Figure 13. Ratio of recovered energy with PaTs and wasted energy in PRVs.

Indeed, the effectiveness of this solution was confirmed through sensitivity analysis performed in Case 4. Reducing the minimum allowable pressure downstream of the branch of the WDN from 4 to $3.5 \mathrm{bar}$, an increase of flow-rate fluctuations occurred, thus justifying the use of a PaT speed-control strategy. An increase of energy recovery equal to $36 \%$ compared to Case 1 was obtained. Through Case 4, it was also demonstrated that the amount of the flow rates that can be exploited by PaTs plays a key role in choosing an adequate control strategy.

The variation of $\mathrm{PaT}$ rotational speed for only controlling downstream pressure without matching the BEP condition, as described in Section 4.3, would allow to exploit all flow rates and achieve an energy recovery that is $23 \%$ higher than the one obtained in Case 1 . To better highlight these aspects, Figure 14 shows flow rates exploited by PaTs depending on the selected control strategy.

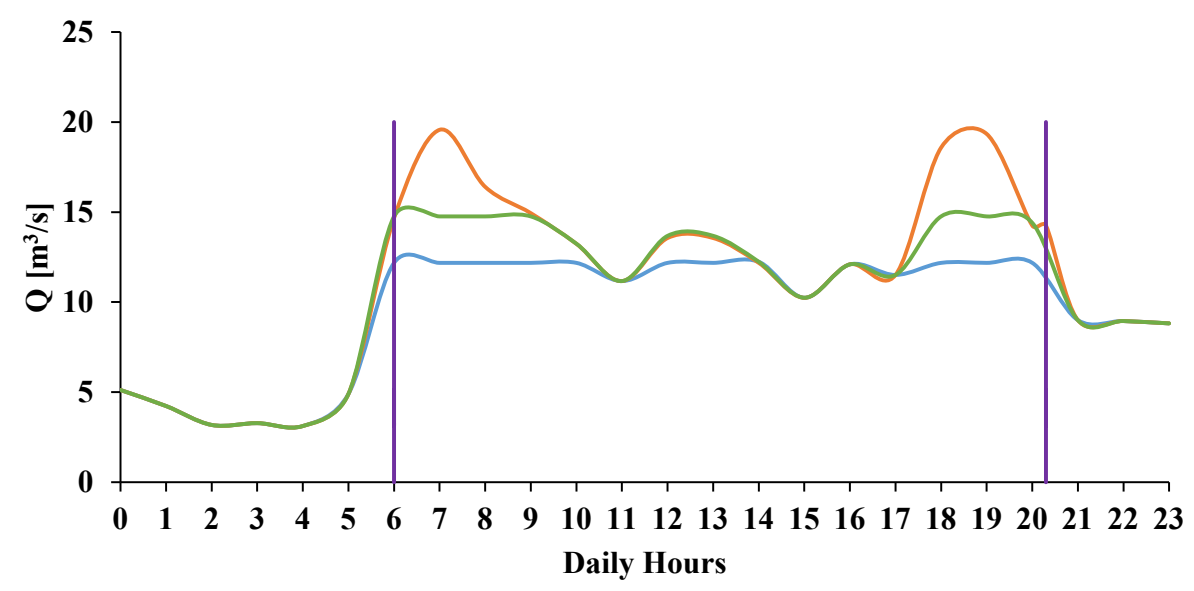

Case 1 and Case $2-$ Case $3-$ Case 4

Figure 14. Comparison of flow-rate variations in different cases.

Maximum flow rate that could be exploited by PaTs in Cases 1 and 2 was equal to $14.35 \mathrm{~m}^{3} / \mathrm{h}$ and it led to a significant bypass of flow rates during the day, thus affecting the effectiveness of energy recovery. The only advantage recorded in Case 2 was the possibility of having a speed-control strategy that helps PaTs to optimally exploit flow rates lower than $14.35 \mathrm{~m}^{3} / \mathrm{h}$, thus always operating at their BEP. However, if flow-rate variations are limited, advantages in terms of energy recovery are minimal.

On the other hand, if speed control is applied when high variability of flow rates exists, without imposing a maximum allowable flow rate like in Cases 1 and 2, the bypass of part of the flow rates can be avoided, thus increasing energy recovery. This strategy consists of reducing PaT rotational speed, 
therefore letting it operate with a flow rate that is higher than the BEP one for the selected rotational speed. This strategy also allows to meet the downstream-pressure constraint and to elaborate the whole available flow rate. However, as shown in Figure 10, efficiency reduction is limited when PaTs operate with flow rates slightly higher than the BEP one. Therefore, the advantage of elaborating a higher flow rate offsets the lower efficiency of the process.

Finally, Case 4 shows sensibility analysis on downstream pressure in terms of recoverable energy by using the same control strategy as that applied in Case 2. Obviously, as available head exploited by the PaTs was increased of about $5 \mathrm{~m}$, and the maximum allowable flow rate was increased by up to $19.57 \mathrm{~m}^{3} / \mathrm{h}$, as well as energy recovery, listed in Table 5. Indeed, these considerations can also be seen in Figure 11, where the trend of the mechanical efficiency in various cases is shown. Case 4 allowed PaTs to operate with higher variability of flow rates and, thanks to speed control, at their BEP. Compared to Case 3, the control strategy in Case 4 allows to recover a higher amount of energy from the WDN branch: a lower flow rate is exploited but higher head is available; thanks to speed control, PaTs always operate at their BEP.

\section{Conclusions}

In this paper, an energy-recovery application in the WDN of Laives located in South Tyrol (Italy) was presented. A measurement campaign was carried out in the analyzed WDN in order to define available flow rates that PaTs could exploit. The branch with the highest variability of flow rates was chosen as the case study since this operating condition is the most critical to evaluate the effectiveness of installing PaTs.

Two analytical models were used to select the proper PaT according to the average value of the flow rate derived from the operational data of the WDN branch obtained in the measurement campaign. Model correlations were also employed to forecast the performance of PaTs at both BEP and off-design operating conditions. An installation layout of two PaTs in series was chosen in order to efficiently exploit all available net head.

A MATLABC-Simulink model was developed in order to simulate the operation of the WDN branch when PRVs were replaced with PaTs, and to estimate the energy recovery that could be achieved adopting the analyzed operating strategies. The MATLAB@-Simulink model is constituted by various elements that resemble the components of a WDN branch, such as (i) input daily flow rate, (ii) pressure-regulation systems, and (iii) PaT speed-control blocks.

Four different operating strategies were analyzed in order to find the best solution in terms of energy recovery. In Case 1, simple flow-rate control was simulated in order to keep the downstream pressure of the WDN branch fixed at 4 bar through the bypass of flow rates higher than the BEP, which was equal to $14.35 \mathrm{~m}^{3} / \mathrm{h}$. In Case 2, PaT speed control was implemented to let PaTs always operate at their BEP, and when flow rates lower than $14.35 \mathrm{~m}^{3} / \mathrm{h}$ were available. In Case 3, an advanced pressure-control strategy was applied by varying PaT rotational speed in order to exploit all available flow rates. In this case, the aim of the speed-control strategy was to keep the downstream pressure constant and equal to 4 bar, also with flow rates higher than the BEP; this is done by reducing the rotational speed of the machine when operating off-design. The reduction of hydraulic efficiency is offset by the higher exploited flow rate. Finally, in Case 4, sensitivity analysis on the decrease of the downstream pressure of the WDN branch was performed, which was reduced from 4 to 3.5 bar. The flow rate exploited by PaTs, as well as the net head, were increased compared to Cases 1 and 2, proving the advantages of lowering WDN operating pressures in terms of both energy recovery and economic savings.

Results of Cases 1 and 2 did not significantly differ due to the low variability of flow rates below $14.35 \mathrm{~m}^{3} / \mathrm{h}$; indeed, the amount of recovered energy was $1.5 \%$ higher than that of Case 1 . On the other hand, Case 3 showed significant improvement, leading to an increase of about $23 \%$ in terms of energy recovery with respect to Case 1 . Finally, Case 4 showed the effectiveness of a speed-control strategy that lets PaTs operate at their BEP in the case of strongly variable operating flow rates. In this case, 
energy recovery was $36 \%$ higher than the one obtained in Case 1, which led to the best result among the analyzed control strategies.

Future developments of the present work are the validation of the developed model with the measurement campaign on-site, as well as detailed Operative and Maintenance (O and $M)$ cost analysis when PaTs are installed. However, results obtained by this MATLAB@-Simulink model give an overview of the potential advantages of using control strategies on PaTs when they operate with highly variable flow rates.

Author Contributions: Investigation, J.C.A., M.R. (Massimiliano Renzi) and M.R. (Mosè Rossi); Methodology, Writing—original draft, J.C.A.; Software, J.C.A.; Conceptualization, M.R. (Massimiliano Renzi); Writing-review \& editing, M.R. (Massimiliano Renzi), M.R. (Mosè Rossi) and G.R.P.; Resources and Funding acquisition, M.R. (Maurizio Righetti); Visualization, G.R.P.; Supervision, M.R. (Mosè Rossi) and M.R. (Massimiliano Renzi).

Funding: This research was funded by the Autonomous Province of Bozen/Bolzano-Italy for University Research-2014 within the Research project "AI-ALPEN", grant number B26J16000300003 and by the EFRE-FESR project "TURB_HYDRO, Hydrokinetic turbines, optimization for sustainable production (ERDF 2018-2021), grant number I56C18000040009". The APC was funded by the 'Open Access Publishing Fund of the Free University of Bozen/Bolzano.

Acknowledgments: The authors wish to thank the Autonomous Province of Bozen/Bolzano for the support received.

Conflicts of Interest: The authors declare no conflict of interest.

\section{References}

1. Nassar, I.A.; Hossam, K.; Abdella, M.M. Economic and environmental benefits of increasing the renewable energy sources in the power system. Energy Rep. 2019, 5, 1082-1088. [CrossRef]

2. Silva, M.; Leal, V.; Oliveira, V.; Horta, I.M. A scenario-based approach for assessing the energy performance of urban development pathways. Sustain. Cities Soc. 2018, 40, 372-382. [CrossRef]

3. Balkhair, K.S.; Rahman, K.U. Sustainable and economical small-scale and low-head hydropower generation: A promising alternative potential solution for energy generation at local and regional scale. Appl. Energy 2017, 188, 378-391. [CrossRef]

4. Yuksel, I. Water management for sustainable and clean energy in Turkey. Energy Rep. 2015, 1, 129-133. [CrossRef]

5. Punys, P.; Dumbrauskas, A.; Kvaraciejus, A.; Vyciene, G. Tools for Small Hydropower Plant Resource Planning and Development: A Review of Technology and Applications. Energies 2011, 4, 1258-1277. [CrossRef]

6. Patsialis, T.; Kougias, I.; Kazakis, N.; Theodossiou, N.; Droege, P. Supporting Renewables' Penetration in Remote Areas through the Transformation of Non-Powered Dams. Energies 2016, 9, 1054. [CrossRef]

7. Korkovelos, A.; Mentis, D.; Siyal, S.H.; Arderne, C.; Rogner, H.; Bazilian, M.; Howells, M.; Beck, H.; de Roo, A. A Geospatial Assessment of Small-Scale Hydropower Potential in Sub-Saharan Africa. Energies 2018, 11, 3100. [CrossRef]

8. Renzi, M.; Rudolf, P.; Stefan, D.; Nigro, A.; Rossi, M. Installation of an axial Pump-as-Turbine (PaT) in a wastewater sewer of an oil refinery: A case study. Appl. Energy 2019, 250, 665-676. [CrossRef]

9. Rossi, M.; Nigro, A.; Pisaturo, G.R.; Renzi, M. Technical and economic analysis of Pumps-as-Turbines (PaTs) used in an Italian Water Distribution Network (WDN) for electrical energy production. Energy Procedia 2019, 158, 117-122. [CrossRef]

10. Samir, N.; Kansoh, R.; Elbarki, W.; Fleifle, A. Pressure control for minimizing leakage in water distribution systems. Alex. Eng. J. 2017, 56, 601-612. [CrossRef]

11. van Zyl, J.E.; Clayton, C. The effect of pressure on leakage in water distribution systems. Water Manag. 2007, 160, 109-114. [CrossRef]

12. Righetti, M.; Bort, C.; Bottazzi, M.; Menapace, A.; Zanfei, A. Optimal selection and monitoring of nodes aimed at supporting leakages identification in WDS. Water 2019, 11, 629. [CrossRef]

13. Saldarriaga, J.; Salcedo, C.A. Determination of Optimal Location and Settings of Pressure Reducing Valves in Water Distribution Networks for Minimizing Water Losses. Procedia Eng. 2015, 119, 973-983. [CrossRef] 
14. Wright, R.; Abraham, E.; Parpas, P.; Stoianov, I. Optimized Control of Pressure Reducing Valves in Water Distribution Networks with Dynamic Topology. Procedia Eng. 2015, 119, 1003-1011. [CrossRef]

15. Yang, S.S.; Derakhshan, S.; Kong, F.Y. Theoretical, numerical and experimental prediction of pump as turbine performance. Renew. Energy 2012, 48, 507-513. [CrossRef]

16. Polák, M. The Influence of Changing Hydropower Potential on Performance Parameters of Pumps in Turbine Mode. Energies 2019, 12, 2103. [CrossRef]

17. Binama, M.; Su, W.T.; Li, X.B.; Li, F.C.; Wei, X.Z.; An, S. Investigation on pump as turbine (PAT) technical aspects for micro hydropower schemes: A state-of-the-art review. Renew. Sustain. Energy Rev. 2017, 79, 148-179. [CrossRef]

18. Arpe, J.; Prénant, J.; Dubas, M.; Biner, H.-P. Project Charactéristiques Des Pompes Fonctionnant en Turbines; Rapport Final du Project N ${ }^{\circ}$ 100400/150 497; Ecole d'ingénieurs de Genève, Haute école valaisanne: Genève, Switzerland, 2006; p. 45.

19. Rossi, M.; Renzi, M. A general methodology for performance prediction of pump-as-turbines using Artificial Neural Networks. Renew. Energy 2018, 128, 265-274. [CrossRef]

20. Venturini, M.; Manservigi, L.; Alvisi, S.; Simani, S. Development of a physics-based model to predict the performance of pumps as turbines. Appl. Energy 2018, 231, 343-354. [CrossRef]

21. Rossi, M.; Nigro, A.; Renzi, M. Experimental and numerical assessment of a methodology for performance prediction of Pumps-as-Turbines (PaTs) operating in off-design conditions. Appl. Energy 2019, 248, 555-566. [CrossRef]

22. Frosina, E.; Buono, D.; Senatore, A. A Performance Prediction Method for Pumps as Turbines (PAT) Using a Computational Fluid Dynamics (CFD) Modeling Approach. Energies 2017, 10, 103. [CrossRef]

23. Carravetta, A.; Derakhshan, S.; Ramos, H.M. Pumps as Turbines; Springer Tracts in Mechanical Engineering; Springer: Berlin, Germany, 2018; p. 236.

24. Wang, T.; Wang, C.; Kong, F.; Gou, Q.; Yang, S. Theoretical, experimental, and numerical study of special impeller used in turbine mode of centrifugal pump as turbine. Energy 2017, 130, 473-485. [CrossRef]

25. Carravetta, A.; del Giudice, G.; Fecarotta, O.; Ramos, H.M. PAT Design Strategy for Energy Recovery in Water Distribution Networks by Electrical Regulation. Energies 2013, 6, 411-424. [CrossRef]

26. Du, J.; Yang, H.; Shen, Z.; Chen, J. Micro hydro power generation from water supply system in high rise buildings using pump as turbines. Energy 2017, 137, 431-440. [CrossRef]

27. Lydon, T.; Coughlan, P.; McNabola, A. Pressure management and energy recovery in water distribution network: Development of design and selection methodologies using three pump-as-turbine case studies. Energy Procedia 2017, 114, 1038-1050. [CrossRef]

28. Lima, G.M.; Luvizotto, E.; Brentan, B.M. Selection and location of Pumps as Turbines substituting pressure reducing valves. Renew. Energy 2017, 109, 392-405. [CrossRef]

29. Lima, G.M.; Brentan, B.M.; Luvizotto, E. Optimal design of water supply networks using an energy recovery approach. Renew. Energy 2018, 117, 404-413. [CrossRef]

30. Kramer, M.; Terheiden, K.; Wieprecht, S. Pumps as turbines for efficient energy recovery in water supply networks. Renew. Energy 2018, 122, 17-25 [CrossRef]

31. de Marchis, M.; Milici, B.; Volpe, R.; Messineo, A. Energy Saving in Water Distribution Network through Pump as Turbine Generators: Economic and Environmental Analysis. Energies 2016, 9, 877. [CrossRef]

32. Carravetta, A.; Fecarotta, O.; del Giudice, G.; Ramos, H. Energy recovery in water systems by PATs: A comparisons among the different installation schemes. Procedia Eng. 2014, 70, 275-284. [CrossRef]

33. Delgado, J.; Ferreira, J.P.; Covas, D.I.C.; Avellan, F. Variable speed operation of centrifugal pumps running as turbines. Experimental investigation. Renew. Energy 2019, 142, 437-450. [CrossRef]

34. Mercier, T.; Hardy, C.; Tichelen, P.V.; Olivier, M.; de Jaeger, E. Control of variable-speed pumps used as turbines for flexible grid-connected power generation. Electr. Power Syst. Res. 2019, 176, 105962. [CrossRef]

35. Alberizzi, J.C.; Renzi, M.; Nigro, A.; Rossi, M. Study of a Pump as Turbine (PaT) speed control for a Water Distribution Network (WDN) in South-Tyrol subjected to high variable water flow rates. Energy Procedia 2018, 148, 226-233. [CrossRef]

36. Renzi, M.; Rossi, M. A generalized theoretical methodology to forecast flow coefficient, head coefficient and efficiency of Pumps-as-Turbines (PaTs). Energy Procedia 2019, 158, 129-134. [CrossRef]

37. SEAB, Servizi Energia Ambiente Bolzano. Available online: https://www.seab.bz.it/it/privati/lacqua-dibolzano (accessed on 3 December 2019). 
38. Singh, P.; Nestmann, F. An optimization routine on a prediction and selection model for the turbine operation of centrifugal pumps. Exp. Therm. Fluid Sci. 2010, 34, 152-164. [CrossRef]

39. SNPA, XII Rapporto Qualità Dell'Ambiente Urbano-Edizione 2016. Available online: http: / /www.isprambiente.gov.it/it/pubblicazioni/stato-dellambiente/xii-rapporto-qualita-dell2019ambienteurbano-edizione-2016 (accessed on 3 December 2019).

40. AEEG, Relazione Annuale Sullo Stato Dei Servizi E Sull'Attività Svolta. Available online: https://www. arera.it/it/dati/eepcfr2.htm (accessed on 3 December 2019).

41. Luo, J.; Wang, J.; Fang, Z.; Shao, J.; Li, J. Optimal design of a high efficiency LLC resonant converter with a narrow frequency range for voltage regulation. Energies 2018, 11, 1124. [CrossRef]

2019 by the authors. Licensee MDPI, Basel, Switzerland. This article is an open access article distributed under the terms and conditions of the Creative Commons Attribution (CC BY) license (http://creativecommons.org/licenses/by/4.0/). 